Cuatro, múltiples moradas (un lugar para los pasajes discursivos)

\title{
Semias fílmicas en una novela policiaco-existencial de Mario Lacruz: El inocente (1953)
}

\author{
Jiménez Gómez, Cristina
}

Cristina Jiménez Gómez Sobre la autora Universidad de Córdoba , España

\author{
El hilo de la fábula \\ Universidad Nacional del Litoral, Argentina \\ ISSN: $1667-7900$ \\ ISSN-e: 2362-5651 \\ Periodicidad: Anual \\ vol. 19 , núm. 21,2021 \\ revistaelhilodelafabula@fhuc.unl.edu.ar
}

Recepción: 24 Diciembre 2020

Aprobación: 10 Febrero 2021

DOI: https://doi.org/10.14409/hf.v0i21.10568
Resumen: La historia de las relaciones entre el cine y la literatura ha sido constante, prevaleciendo el estudio de las adaptaciones cinematográficas de obras literarias en el campo del comparatismo. Se ha desatendido, así, otro tipo de interferencias que se producen entre ambos medios como es el influjo de los códigos fílmicos en la literatura. Desde esta perspectiva, el propósito de este trabajo es demostrar cómo Mario Lacruz, en su novela El inocente (1953), recurre a las semias fílmicas para construir el punto de vista, el tiempo y el espacio narrativos.

Palabras clave: Literatura comparada, Cine y literature, Semias fílmicas, Mario Lacruz, El inocente.

\begin{abstract}
The history of the relationship between cinema and literature has been constant, and has had as its main topic of interest the study of film adaptations of literary works in the field of comparatism. However, other types of interferences that occur between both media, such as the influence of flim codes on literature have been neglected. From this perspective, the purpose of this paper is to demonstrate how Mario Lacruz, in his novel El inocente (1953), uses film semias to construct the narrative point of view, time and space.
\end{abstract}

Keywords: Comparative literatura, Cinema and literatura, Film semias, Mario Lacruz, El inocente.

\section{Introducción}

Desde que apareciera el cinematógrafo de la mano de los hermanos Lumière a finales del siglo XIX, el cine se concibió en seguida como «un medio capacitado para contar historias, lo que lo emparentaba con toda una tradición narrativa esencialmente literaria» (Peña-Ardid, 1992:54). El cine nació, así, como el «pariente pobre» de la literatura acudiendo a los tramas y personajes de melodramas y folletines novelescos debido, en gran medida, a su aspiración a ser reconocido como arte. Desde ese momento, comienza una larga historia conflictiva entre la literatura y el cine en términos de fidelidad y de debates teóricos que continuaran hasta la actualidad en torno al concepto de «adaptación cinematográfica» (Pérez Bowie, 2003 y 2008). Todo ello no hace sino poner en evidencia el protagonismo y la influencia que la literatura ha tenido en el nacimiento y destino del cine, pero, también, el insuficiente estudio de la impronta fílmica en la literatura. Como explica Peña-Ardid (1992: 76), solo los teóricos franceses se acercaron a esta cuestión en dos líneas distintas en los años 
cincuenta: Claude-Edmonde Magny con su ensayo L'age du roman americain (1948) sobre la influencia del cine en las técnicas de la novela norteamericana de los años veinte y las teorías del précinéma -E. Fuzellier, H. Agel y P. Leglise, entre otros-, que trataron la existencia de estructuras cinematográficas (la esencia visual y el movimiento) en obras literarias anteriores a la invención del celuloide en los años cincuenta y sesenta. Así pues, se encontraron, por ejemplo, estructuras cinematográficas en los hitos literarios clásicos de Homero y Virgilio (Fuzellier, 1964 y Leglise, 1958), dando cuenta de la existencia de un cine antes de un cine.

En España, al igual que en Italia, la tesis de Magny tuvo cierta difusión a

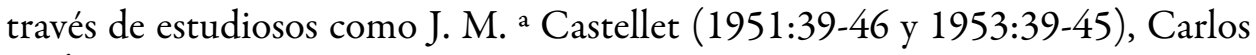
L. Álvarez (1960:44-45) y M. Alvar (1968:253-270). De la misma manera, las teorías del précinéma se divulgaron dentro del ámbito nacional, aunque debemos mencionar que reconocidos críticos como Dámaso Alonso ${ }^{1}$ y A. Zamora Vicente, este último con sus apuntes sobre el cinematografismo de Tirso de Molina, advirtieron la impronta fílmica en literatos españoles anteriores al précinéma. Asimismo, hay que destacar los estudios de Joaquín de Entrambasguas (1954); Jorge Urrutia (1984), quien hizo un repaso de la influencia de los procedimientos cinematográficos en la poesía española; Peña-Ardid (1992); Darío Villanueva (2006:211-213), estudioso de los elementos precinematográficos en El Qujiote; o, más recientemente, Hermosilla (2020:213-227), con su trabajo sobre la transposición de los códigos cinematográficos en un cuento de Ignacio Aldecoa. Así pues, si bien no ha habido un amplio corpus de trabajos que haya abarcado este tema de una forma regular, metódica y concreta, la crítica ${ }^{2}$ de las últimas décadas ha abierto nuevas líneas de investigación al dirigir su atención hacia el estudio de otras semias no lingüísticas, como las fílmicas, en obras literarias. Desde esta perspectiva, pretendemos analizar la novela El inocente (1953), de Mario Lacruz.

\section{Mario Lacruz: un editor-autor infatigable}

Pese a que el barcelonés Mario Lacruz (1929-2000) contaba con una vasta producción literaria (cuentos, ensayos y una diversa tipología de novelas) e, incluso, cinematográfica (tres guiones escritos para cine), descubierta póstumamente en su armario junto a las herramientas de bricolaje, solo se ha publicado una ínfima parte hasta el momento: el volumen de cuentos Un verano memorable y otras historias (1955) y las novelas El inocente (1953), La tarde (1955) y El ayudante del verdugo (1971), publicadas en vida del autor y reeditadas póstumamente en el volumen titulado Trilogía de la culpa (2009). No obstante, su condición de autor, solapada por la de editor literario durante cuarenta y cinco años en editoriales como Plaza y Janés, Argos Vergara y Seix Barral, se asomaba siempre por cualquier recóndito rincón de su existencia. En palabras de su hijo Max Lacruz (Muñoz Carvajal, 2015), su padre «siempre se consideró un escritor metido a editor: no tenía vocación de editor, y al final el editor se comió al autor». Aun así, Lacruz será recordado como uno de los editores más respetados y reconocidos ${ }^{3}$ en el ámbito hispánico, labor estrechamente ligada no solo con su tarea de traductor sino también con su saber literario, atestiguado por la cantidad de libros de autores españoles -Francisco Umbral, 
Julio Llamazares o Rosa Montero-y extranjeros - Goethe, Wilde, Stevenson, Sciascia, Tournier, Kundera, Montanelli, Vladimir Nabokov, Gabriel García Márquez, Mario Vargas Llosa, José Saramago y Fernando Pessoa, entre otrosque editó en la España franquista. Como demostraremos en el análisis de la novela El inocente, Lacruz, tanto en su faceta de editor como de autor, se caracterizó por una visión narrativa innovadora (subjetivismo, fragmentación, interacción de códigos literarios y fílmicos), que iba a contracorriente de las modas literarias nacionales de la posguerra en torno al objetivismo y el realismo social con obras como La colmena (1951) de Camilo José Cela, La Noria (1952) de Luis Romero y El Jarama (1956) de Rafael Sánchez Ferlosio.

\section{El inocente (1953) y su cinematografismo}

Si bien la novela El inocente fue prontamente adscrita al género policiaco, debido, en gran medida, al premio Simenon de novela policiaca (editorial Aymá) que recibió en 1953, el relato se mueve en terrenos difusos. Esta catalogación genérica fue puesta en entredicho por el mismo autor en tanto que no podemos hablar de una novela estrictamente policiaca porque, si bien hay elementos de esta, «se rompe una de sus reglas: que alguien se entere de lo que ha ocurrido y cómo ha ocurrido (...). Quizá esa función recaiga sobre el lector» (Lacruz, 1984:216). En la misma línea se expresa José F. Colmeiro (1994:141) cuando explica que, desde el principio, el lector sospecha que no se ha cometido ningún crimen y que el protagonista, Virgilio Delise, es inocente. Se nos propone una novela donde el acusado no es culpable y el único asesinato que se cometerá impunemente será el del propio Delise a manos de un joven e inexperto oficial, lo que quedará silenciado por la policía y los medios de comunicación. Es un contexto ficticio que, indudablemente, se vincula con la etapa histórica de la España franquista, dominaba por el miedo, la corrupción, la acusación infundada y la persecución política. $^{4}$

La intriga narrativa se aleja, pues, del juego deductivo del whodunit clásico en tanto que la historia no depende de la ocultación y desenmascaramiento de un culpable, sino que se construye en torno al descubrimiento de los motivos - la ambición del inspector Doria - de la persecución del protagonista y del sentimiento de culpabilidad «casi congénito» del perseguido. Este es un acomodado musicólogo que es acusado del crimen de su padrastro Loreto Montevidei, un exguerrillero y militante político de setenta y dos años, con pruebas manipuladas por inspector Doria. En realidad, la autopsia demuestra que la muerte fue accidental a causa de una dosis excesiva de digital, un estimulante para el corazón. No obstante, ni la autopsia, ni los testimonios, ni las pruebas serán tenidos en cuenta por Doria y el resto de los policías, movidos por la ambición de conseguir un ascenso y la gloria mediática. Así pues, el protagonista se verá envuelto en una incesante huida que le llevará no tanto a demostrar su inocencia como a desentrañar un sentimiento de culpabilidad, inherente a él, a partir de la reflexión de su pasado.

Más allá del argumento, lo significativo del estilo lacruciano se manifiesta en un relato eminentemente visual, fragmentario y austero, casi telegramático por momentos. Se observan, así, rasgos de la novela experimental y posmoderna que se desarrollaría posteriormente a partir de la combinación de ingredientes propios 
de la intriga policiaca, como el examen de las pistas e indicios, las declaraciones de los testigos y la persecución del supuesto culpable, con «elementos de la novela "literaria" de vanguardia (como profundidad psicológica, multiplicidad de niveles, textura rica, perspectivismo, técnica de contrapunto, experimentación formal, ruptura del orden lógico-temporal, etc.)» (Colmeiro, 1994:141). El carácter híbrido - policiaco y existencial- ${ }^{5}$, pero también las «visiones» cinematográficas, especialmente en el protagonista, consiguen construir un relato caracterizado por la sonoridad, lo visual, el movimiento y el subjetivismo. Como Hart (1987:27) apunta, gracias a los «cinematic glimpses of Delise's part, we learn of his disastrous childhood - his father's death when Delise was a small child; his mother's remarriage to a coarse, (...); his love for his stepsister, Fioreya» (Hart, 1987:27).

Estamos, pues, ante una novela que se construye mediante códigos propiamente cinematográficos y otros compartidos con la literatura. A este respecto, Christian Metz (1973:258-281) ya distinguió entre códigos específicos del lenguaje cinematográfico y otros no específicos en tanto que son compartidos con otros lenguajes y medios; se refirió así a las «interferencias semiológicas entre lenguas». Con relación al lenguaje audiovisual, y el cine en particular, Metz identificó cinco sustancias diferentes de la expresión: la imagen fotográfica en movimiento, los ruidos, el lenguaje verbal hablado, el sonido musical registrado y los rastros gráficos (títulos, créditos, etc.). Unas décadas después, Seymour Chatman (1992:24) también explicaba que la tradicional división estructuralista de toda narración en historia (fable) - el plano del contenido-, y discurso (sujet) —el plano de la expresión-, no era suficiente para dar cuenta de su estructura semiótica de manera que, siguiendo los postulados sausseaurianos y hjelmslevianos, distinguió una forma y una sustancia de la expresión, y una forma y una sustancia del contenido. A la hora de abordar la novela de Lacruz, analizaremos la transposición de códigos específicamente cinematográficos, pero también aquellos que comparten la literatura y el cine con objeto de analizar el punto de vita, el tiempo y el espacio del discurso narrativo.

\section{Elpunto de vista: la cámara subjetiva}

En la novela que nos ocupa se advierte lo que Chatman (1990: 172) denomina como «cámara subjetiva», es decir, la visión del espectador se identifica con la del personaje, como si la lente de la cámara estuviera detrás de los ojos de este último. Con relación al punto de vista (¿quién ve?) en el cine, podemos hablar también de una «ocularización interna» en términos de A. Gaudreault y J. Fost (1995: 141) cuando un plano está anclado en la mirada de una instancia interna a la diégesis. Se descubre, así, la materialidad de un cuerpo o la presencia de unos ojos que permiten identificar un personaje observando. En el relato de Lacruz, el narrador, valiéndose de una focalización interna no en el sentido estricto en primera persona (Genette, 1989: 247), sino en tercera persona, nos describe lo que Delise ve, piensa y siente. Tras ser detenido, mientras está siendo conducido hacia la jefatura de policía en un auto, se registra el movimiento de la mirada del protagonista desde su posición en el asiento trasero. Como si se tratase de sucesivos planos detalle, aparecen los elementos que observa y también los que recrea en su mente: en primer lugar, el cuadro de velocidad del auto; 
en segundo lugar, el parabrisas o vidrio frontal a través del cual se podía ver el ángulo que formaban los bordes de la carretera; $y$, en tercer lugar, la imagen dada por un recuerdo infantil y producida cuando, siendo un niño y acompañado de su padrastro Loreto Montevidei, se aproximaba a la boca de los túneles de una atracción. Se obvia cualquier alusión al cuerpo completo de Delise, solo aparecen sus ojos y lo que estos ven o vieron de forma fragmentada:

\footnotetext{
Delise tenía los ojos fijos en el cuadro de velocidad, observando las oscilaciones de la aguja lleno de sombríos presagios. La marcha era casa vez más apresurada. Habían llegado a la carretera principal, nivelada y recta, cuyos bordes formaban un ángulo perfecto en el horizonte. La marcha era cada vez más apresurada. Delise pensó en el tobogán por el que se deslizaba siendo niño los domingos por la mañana en el parque de atracciones, y el espanto con que veía aproximarse la boca de los túneles; se encogía todo lo posible en el frágil asiento y gimoteaba como un necio al ver los orificios oscuros sin atreverse a mirar a su padre, que los desafiaba con toda la arrogancia de su tamaño (Lacruz, 1984:11).
}

Nótese en el texto la técnica de la yuxtaposición cinematográfica en la que, por medio de un flashback - la analepsis en el texto literario-, se encadenan, de manera abrupta, la imagen del cuadro de velocidad, la de la carretera y la del tobogán y los túneles en el parque de atracciones. Al acercarse a la jefatura de policía, la sensación de peligro y terror de Delise se potencia por la velocidad del auto, lo que le lleva a acordarse de la misma sensación que tuvo en un momento de su infancia cuando se aproximaba a la boca de los túneles oscuros de una atracción. Este recuerdo infante está estrechamente vinculado con el rechazo acérrimo que sentía por el hombre al que era obligado a llamar «padre», Loreto Montevidei.

Son muchas las ocasiones en que encontramos marcas textuales que recrean el uso de la cámara subjetiva a partir de cómo la mirada fragmenta las personas y los objetos que contempla. Por ejemplo, cuando Virgilio Delise, después de saltar del auto de policía e iniciar su huida, se detiene junto a una columna de cartelones de propaganda en la calle. En ese instante, solo puede leer parte de los cartelones porque, al estar superpuestos unos sobre otros, no toda la información está a la vista. Asimismo, cuando su mirada se detiene en un cartel rasgado, tiene que completarlo mentalmente: «Grandes mayúsculas tapadas por otras mayúsculas más recientes. Películas y productos para lavar la ropa. Había un cartel rasgado: CONCERTO GRO... «Grosso» —completó mentalmente —» (Lacruz, 1984:40). Nótese aquí cómo Delise visiona distintos anuncios y cómo el uso de las mayúsculas y la fragmentación lingüística en «CONCERTO GRO...» reproducen la imagen exacta del cartel que contempla el personaje, tal como si interviniese la cámara subjetiva. Esto mismo lo encontramos en otros momentos de la novela cuando el protagonista llega al pueblo de Fonte-Lidia y lee el letrero del hostal donde va a hospedarse - $\ll$ COMIDA Y ESTANCIA FAMILIAR—» (p. 159), o cuando, al ser descubierto en Fonte-Lidia y huyendo del inspector Doria, se interpone en su visión, a modo de salvación, el letrero del autocar que se dirigía a Escala — «vio el letrero debajo de los equipajes sujetos en la baca y leyó el nombre: ESCALA» (p. 175).

Sin embargo, la técnica de la cámara subjetiva no solo se supedita a registrar la mirada del protagonista, sino también la de otros personajes que carecen de importancia para el desarrollo de la acción. Este es el caso del pescador miope 
y las dos mujeres gruesas que están almorzando en la playa. Ellos observan cómo Delise, que trata de esconderse y pasar desapercibido, se va acercando hacia ellos en la playa. En un primer momento, solo avistan un «borrón» en la lejanía — nótese aquí cómo si la técnica cinematográfica del desenfoque o foco difuminado de la cámara recrease la percepción natural del ojo humano-; y, después, conforme el fugitivo se va acercando a ellos, se produce un mayor enfoque. En este momento, las miradas realizan un movimiento ascendente, desde sus tobillos y zapatos hasta su camisa y corbata. Se recrea así el movimiento panorámico vertical de una cámara que, como si estuviera fija y situada sobre un trípode, se mueve de abajo a arriba mimetizando el mismo movimiento que realiza la mirada del pescador y las dos mujeres en la playa. A partir de los detalles (los zapatos de piel, la camisa y la corbata), se dan cuenta de que Delise no es un pescador, sino un hombre acaudalado. Finalmente, a medida que el protagonista se va acercando, el pescador miope lo identifica como el hombre que había visto previamente en la foto del periódico: es el fugitivo que la policía busca. Cuando Delise se marcha, los ojos del pescador miope, con dificultad para ver de lejos, volverán a ver «una pálida mancha blanca - la de su camisa - bajo la roca áspera cubierta de matas achaparradas» (145).

Por último, debemos señalar que el subjetivismo cinematográfico también se produce en la identificación del espectador con el relato fílmico a través del sonido filtrado por el personaje. Es lo que A. Gaudreault y J. Fost (1995:146) denominan como «auricularización interna secundaria» porque se filtran sonidos a través de un personaje que está presente en la imagen gracias al montaje, o a la propia representación visual. En El inocente se advierte esta técnica cuando Virgilio y Muoli, el periodista que pretendía ayudarlo a demostrar su inocencia, acuden a la casa de Marcelu con el fin de que este confirmara públicamente la coartada del acusado: que había estado jugando una partida de ruleta en su casa en la noche del asesinato de Montevidei. Sin embargo, la inesperada presencia de un misterioso automóvil con la capota echada y los faros apagados, estacionado en la zona, frustra la posible conversación, dejando abatido a Delise. Este observa con impasividad al periodista y, abstraído, apenas escucha las palabras de Muoli, que está sentado a su lado. En el texto, se utiliza una comparación para subrayar el efecto del sonido entubado, utilizado también en el cine mediante el uso de los filtros reductores de ruido: «Delise lo miró con la impasibilidad de quien se ha inhibido por completo. Su voz sonó como si hablara desde el fondo de una habitación cerrada o de un túnel» (92).

\section{El tiempo}

\section{La cámara lenta}

Como explica Chatman (1990:77), el cine dispone de procedimientos como el montaje encabalgado y la cámara lenta para producir la técnica del «alargamiento», que consigue que la duración del tiempo del discurso sea mayor que la del tiempo de la historia. Sin embargo, la literatura dispone de recursos lingüísticos fónicos, morfosintácticos y semánticos para acelerar o enlentecer el ritmo narrativo. Recordemos que ya Lessing en su Laocoonte (1766) diferencia entre las artes temporales (la poesía y, por extensión, las artes escritas) y las 
espaciales (la pintura y, por extensión, las artes visuales), según plasmen con más fidelidad el tiempo o el espacio respectivamente.

En El inocente, la cámara lenta se recrea especialmente cuando se nos cuenta lo que acontece en la mente de Virgilio Delise, de manera que la percepción del tiempo se supedita a sus sentimientos. Un ejemplo se evidencia cuando el protagonista, durante su huida, se dirige a la estación para tomar un tren desde Escala hacia Fonte-Lidia, la ciudad donde se encuentra la casa familiar, la casa de su padre biológico Matías. En ese momento se queda inmóvil y absorto en una ventana de la calle que reflejaba los rayos del sol y piensa en una anécdota de su infancia. Recuerda cuando, siendo un niño, acudió junto a su madre Helena a la consulta médica de su padre, el otorrinolaringólogo Matías Delise, que solía llevar una lámpara sujeta a su cabeza mediante una correa para examinar a los pacientes. En el texto, la ralentización del ritmo narrativo se consigue mediante el uso de la anadiplosis — «es/era un guerrero bueno»-, el paralelismo anafórico — «(Papá) tiene un casco brillante» - y las mismas palabras repetidas por la madre, el narrador y el niño Virgilio:

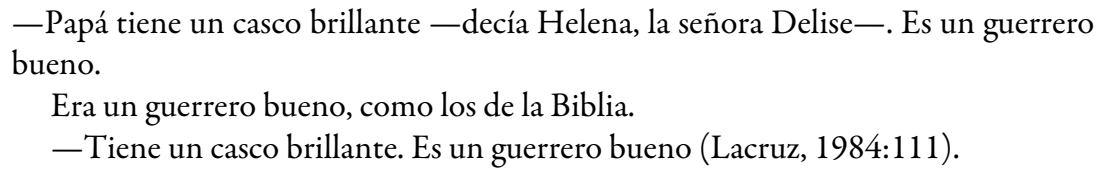

Se intensifica, así, la nostalgia de Virgilio por un pasado infantil irrecuperable y vinculado a su padre, Matías Delise, que está muerto en el presente. El regreso a la casa familiar en Fonte-Lidia aparece como la única vía posible de recuperar ese pasado feliz y protector («todo volvería a ser como antes»; «él sería otra vez el niño», 117) dado por el «guerrero con casco brillante».

De la misma manera, la sorpresa y la incredulidad de Muoli ante las respuestas que Virgilio le está ofreciendo en su primer encuentro, después de la fuga, se revelan en el alargamiento temporal del discurso. En el texto, se recurre a una comparación - el ruido de un disparo- para describir cómo las palabras del periodista llegaban a ser percibidas por el protagonista un tiempo después de ser proferidas, justo después de percibir los gestos, muecas y movimientos del periodista. Lo que en la historia dura un instante, en el discurso se dilata gracias al uso de los gerundios «parpadeando»y «gesticulando», que en el texto expresan una acción en curso en un momento del pasado, y el uso de la comparación:

- ¿Has visto a tu cuñado? ¿Cuándo?

- Sí, he hablado con él hace poco; en su casa. Me ha dicho que pensaba llamar a la policía.

Muoli se le acercó parpadeando, gesticulando como un actor. (El escenario, sin embargo, estaba lejano, porque las palabras llegaban después de los ademanes, como el ruido de un disparo, siempre posterior al fogonazo.) (Lacruz, 1984:84).

\section{El montaje alterno o alternado}

A principios del s. XX, D. W. Griffith descubrió, leyendo a Dickens, que podía intensificar cualquier escena si, en lugar de resolverla directamente en una toma, la alargaba mediante la alternancia de varias acciones que sucedían al mismo tiempo en escenarios distintos. En la novela de Lacruz, el montaje alterno se establece por asociación temporal de varias acciones que ocurren en 
lugares divergentes, lo que se expresa textualmente a través del uso significativo y recurrente del paréntesis. Veamos un ejemplo:

El interior del coche estaba casi vacío. Después de elegir un rincón soleado, Delise reclinó la cabeza contra la ventanilla y no tardó en quedarse dormido. Debían de ser las ocho y media cuando el revisor llamó su atención cuidadosamente. (En aquel momento el párroco de Santa Adria sacudía a su sobrino por los hombros.) Delise abrió los ojos para ver la cara del revisor inclinada sobre él, y su propia imagen reflejada por partida doble en las pupilas del revisor (Lacruz, 1984:118).

En el fragmento anterior se suceden dos acciones: Delise, en la estación de Escala, subiéndose en el vagón del tren que le llevaría de nuevo a su infancia, a la casa familiar - la de su padre Matías Delise - en Fonte-Lidia; y el párroco de la iglesia de Santa Adria, en Escala, sacudiendo a su sobrino, el joven policía inexperto y miedoso que no había sido capaz de disparar a Delise cuando se escapó del auto de policía. La interrupción de la escena del fugitivo, justo cuando está siendo requerido por el supervisor del tren para revisar su billete, dota de suspense y tensión a la narración, lo que también se materializa posteriormente cuando descubrimos la psicosis persecutoria del protagonista, temeroso de ser descubierto: el rincón del vagón en que se hallaba le parece un horno y los viajeros leyendo el periódico donde se había publicado su fotografía se repetían incesantemente e inundaban los vagones y las calles: «periódicos y fotografías se multiplicaron en su imaginación desatada» (121).

Se debe señalar que la sucesión de las dos acciones no solo se produce por asociación temporal, sino también por asociación temática en tanto que se alternan dos imágenes de dos hombres perseguidos por sus miedos, sus frustraciones y su conciencia. Se establece, así, un juego de identidades dobles donde el hilo conductor es la culpa. Por una parte, Delise, pese a no haber cometido el crimen de su padrastro, se cree culpable de este hecho y cualquier otro que pudiera pasar; recordemos que, al principio de la novela, se cuenta que el protagonista está esperando en un hotel a que los dos policías, Selbi y el joven oficial, lleguen a detenerle. Es un sentimiento que se justifica desde su infancia debido al odio acérrimo que siente por su maltratador padrastro y a la imposibilidad de estar con su amada hermanastra Fioreya, quien, poco después de casarse con Lucius Costa, falleció. Por otra parte, el joven policía, sin vocación, fue un campeón de Rugby que, debido a una lesión, terminó con una prótesis de metal en su pierna. Al principio, no tiene la sangre fría para disparar a Delise ni el grado de corrupción de sus otros compañeros, pero, una vez asimile y acepte cómo funciona el sistema, disparará su arma reglamentaria contra el fugitivo inocente. Recordemos que su tío párroco, quien siempre le regañaba por las travesuras infantiles, aparece como juez y lo califica de verdugo en su encuentro en la iglesia: «-Dime; madrugas mucho, ¿no es cierto?, desde que te has convertido en un verdugo policía» (107).

En el texto, el paso de una acción a otra aparece representado por una oración parentética que destaca por su concisión y brevedad, a modo de una transición rápida de imágenes en pantalla, que, aunque interrumpe la línea principal de la narración acerca de cómo se va desarrollando la huida del protagonista, no desorienta al lector debido a la coherencia de contenido existente entre las dos escenas. Este recurso se vuelve a repetir poco después cuando el fugitivo, que está buscando el billete que le reclama el supervisor del tren, se percata de su fotografía 
en el periódico que estaba leyendo el viajero de enfrente. Al mismo tiempo, en la iglesia, el joven policía está leyendo los titulares del mismo periódico:

\begin{abstract}
Buscó en sus bolsillos, mientras procuraba desvelarse del todo. Entonces vio por primera vez su fotografía en el periódico que leía el viajero de enfrente. La fotografía y los titulares estaban invertidos, pero no cabía duda que era su efigie la que reproducía el periódico. (En aquel momento el policía joven leía los mismos títulos por encima del hombro de su tío.) (Lacruz, 1984:118).
\end{abstract}

\title{
El espacio
}

\section{La plasmación visual}

En nuestra novela se advierte la tendencia a representar perceptivamente el espacio a través de la mirada del personaje. La acción se sitúa en la ciudad provinciana ficticia de Escala y en el pueblo cercano de Fonte-Lidia, ambos escenarios son descritos subjetivamente en torno a las dialécticas luz-oscuridad, color-ausencia de color y pasado-presente. Así pues, la percepción del espacio es eminentemente visual puesto que viene dada por la presencia o ausencia de la luz y del color, lo que se vincula estrechamente con los tiempos pasado (la infancia) y presente (la adultez y la vejez) de los personajes. De la misma manera, en el cine, el uso de la luz y del color son recursos imprescindibles para construir la imagen cambiante del espacio y generar emociones y significados en el espectador. Veamos un ejemplo en el texto:

Junto a la carretera nacía un acantilado profundo, y no había alambre protector. Llegaron a un recodo desde el que podía verse la línea confusa del mar bajo una larga franja brumosa. La brisa — una brisa artificial producida por la velocidad del coche — arrastraba olor de embarcaciones. «Ya falta poco para llegar» —se dijo Delise-; solo quedan unos minutos.» (Lacruz, 1984:12).

El fragmento describe el momento en que Delise está siendo conducido a la jefatura de policía en el anochecer. Se describe lo que la mirada del detenido puede abarcar, el acantilado que había al lado de la carretera sin ningún tipo de barrera protectora y el mar brumoso. El miedo, la confusión y el desconcierto del protagonista ante la proximidad de su destino («solo quedan unos minutos») se dejan notar en los colores turbios, poco claros y grises de la franja brumosa que la neblina formaba encima del mar. Asimismo, se alude a la presencia de una brisa mecanizada y artificial, producida por la velocidad del coche, lo que connota una naturaleza perdida, muerta. Todo ello queda reforzado por las isotopías fónicas mediante la aliteración de los grupos consonánticos / fr/ y / $\mathrm{br} /$ en «franja», «brisa»y «brumosa», que sugieren el carácter impenetrable del mar y los sonidos del oleaje tempestuoso. Asimismo, la aliteración de / 1/ seguida de una vocal sobre la que recae el acento prosódico y ortográfico en «acantilado», «alambre», «larga»y «línea» logra una ralentización del discurso oral, expresando la idea de un interminable acantilado, un mar revuelto y una espesa capa brumosa en el horizonte.

Frente a la oscuridad y la ausencia de la luz en el presente, se antepone la blancura extrema y los objetos aureolados, resplandecientes por la luz del amanecer, cuando Delise recuerda un momento de su niñez en el campo con 
su padre. Como explica Lessing, en cuanto a la plasmación espacial en las artes visuales, se recoge un solo cuadro en un momento dado, en reposo:

El campo estaba cubierto de flores blancas, de una blancura que dañaba las pupilas. Por él iba un hombre llevando a un niño de la mano. Todos los objetos estaban aureolados; la hierba que llegaba hasta la cintura del niño, se extendía por la planicie inmensa, y el aire tenía la transparencia de un Manet (Lacruz, 1984:117).

Nótese cómo la luz, elemento básico en el impresionismo pictórico —de ahí la cita a Édouard Manet-, ofrece una percepción de las flores y la hierba muy distinta a la que pudiera aparecer en el atardecer. Las flores, debido a la salida del sol, parecen tan blancas que dañan la vista y la hierba parece extenderse hasta el infinito. Ahora, las sensaciones que se expresan son reconfortantes y placenteras: aire transparente y limpio, campo florido y con una tonalidad de «oro» debido a la incidencia de los rayos del sol.

\section{El claroscuro}

Sabemos que las narraciones verbales disponen de mecanismos como el uso de calificativos, diminutivos y comparaciones para representar el espacio de la historia. A falta de estos recursos en el cine, adquiere importancia el grado de proximidad de la cámara al objeto (primer plano, plano detalle, plano general, zoom de acercamiento y alejamiento), el ángulo de la cámara (nadir, cenital, picado-contrapicado) y, por supuesto, el grado de iluminación reflejada. En el cine, la técnica del claroscuro se utiliza para crear escenas dramáticas, tenebrosas y/misteriosas, así como para expresar los contrastes y contradicciones de los personajes, sus «luces»y «sombras». En este sentido, el cine policiaco y el cine negro o film noir han sacado el máximo provecho de esta técnica de iluminación en filmes como Laura (Otto Preminger, 1944), El Halcón Maltés (J. Huston, 1941) y La mujer del cuadro (Fritz Lang, 1944).

En El inocente son frecuentes las escenas en que el claroscuro intensifica la intriga policiaca en torno a la persecución de Virgilio Delise, por ejemplo, cuando Selbi y el resto de policías están buscando al fugitivo, que acaba de escaparse del auto y huir hacia un callejón oscuro:

La silueta de un agente se dibujó al otro extremo de la calle agitando los brazos. Selbi indicó que rodearan el bloque de casas. (...) Los regueros luminosos de las linternas desaparecieron, y la calle empezó a bullir de policías que brotaban de los tabiques de cemento. (...) Se podía escuchar esa multitud de sonidos que brotan de las viviendas de los suburbios: el gorjeo de la cañería de desagüe, un altercado familiar o una risa, el llanto de un niño. En la encrucijada de dos callejones salieron los hombres del organillo y vieron a los cuatro policías detenidos junto a una ventana iluminada, que proyectaba sus sombras prodigiosamente alargadas (Lacruz, 1984:24-25).

Obsérvese que el léxico utilizado, «silueta», «se dibujó», «regueros luminosos» (trazos), «brotaban», «brotan», «sombras», remite al campo de las artes plásticas y visuales o a la inmediatez de cómo la imagen fílmica puede aparecer a vista del espectador («brotaban de los tabiques del cemento»). Asimismo, el contraste entre la luz y la oscuridad crea formas aterradoras de sombras alargadas, y el reflejo lumínico de las linternas en el suelo y las paredes avisan a Delise de que los policías se están acercando cada vez más a él, escondido 
tras una puerta en un solar en construcción desde donde atisbaba todo a través de una rendija.

En conclusión, la presencia de semias fílmicas en la novela de Lacruz evidencia la técnica innovadora del autor para elaborar un relato subjetivo y fragmentado en la narrativa española de los años cincuenta. La influencia de los procedimientos cinematográficos (la cámara subjetiva, la cámara lenta, el montaje alterno, etc.) en su novela consiguen sondear, de una manera visual, el mundo psicológico y las acciones de los personajes a la vez que realizar una velada crítica social y política del momento.

\section{Referencias}

Alvar, Manuel (1968). Técnica cinematográfica en la novela española de hoy. Arbor (276), 253-270.

Álvarez, Carlos Luis (1960). Técnicas y gaitas: el relato objetivo. Punta Europa (54), 44-45.

Castellet, José María (1951). Las técnicas de la literatura sin autor. Laye (12), 39-46

Castellet, José María (1953). El tiempo del lector. Laye (12), 39-45.

Chatman, Seymour (1990). Historia y discurso. La estructura narrativa en la novela y en el cine (trad. Fernández Prieto, M. J.). Taurus.

Colmeiro, José F. (1994). La novela policiaca española: teoría e historia crítica. Anthropos.

Entrambasaguas, Joaquín de (1954). Filmoliteratura. Temas y ensayos. CSIC.

Fuzellier, Etienne (1964). Cinema et litterature. Éditions du Cerf.

Gaudreault, André y Jost, François (1995). El relato cinematográfico. Cine y narratología (trad. Puyol, Nuria). Paidós.

Genette, Gérard (1989). Figuras III (trad. Manzano, Carlos). Lumen.

Hart, Patricia (1987). Guilt and innocence in Mario Lacruz. En The Spanish Sleuth: the detective in Spanish Fiction (pp. 26-46). Fairleigh Dickinson University Press.

Hermosilla, María Ángeles (2020). La transposición de códigos cinematográficos al cuento: un ejemplo de Ignacio Aldecoa. El hilo de la fábula (20), 18, 213-227.

Jaime, Antoine (2000). Literatura y cine en España (1975-1995). Cátedra.

Lacruz, Mario (2da. Ed.) (1984). El inocente. Anaya.

Léclise, Paul (1958). Une oeuvre de précinéma: l'Enéide. Debresse.

López, Laura (2009). Mario Lacruz: un autor existencial. Signa (18), 321-343.

Lessing, Gotthold Ephraim (1960). Laocoonte (trad. Raggio, Amalia). UNAM.

Metz, Christian (1973). Lenguaje y cine (trad. Urrutia, Jorge). Planeta.

Montalbán, Manuel (2000). Lacruz o el escritor que aplazó el favor del mar. El País.htt ps://elpais.com/diario/2000/05/15/cultura/958341614_850215.html

Muñoz Carvajal, Bernardo (2015). Vigencia de un infatigable de la edición española (Entrevista a Max Lacruz). Negritas y cursivas.https://n9.cl/1bb2

Nicolás Rubio, César (1982). Del fonema al contexto: sobre un soneto de Manuel Machado. Cuadernos de la Cátedra Miguel de Unamuno (27-28), 181-201. https: //revistas.usal.es/index.php/0210-749X/article/view/9867/10240

Paz Gago, José María (2004). Propuestas para un replanteamiento metodológico en el estudio de las relaciones de literatura y cine. El método comparativo semiótico- 
textual. Signa (13), 199-232. http://revistas.uned.es/index.php/signa/article/vi ew/6095/5830

Peña-Ardid, Carmen (1992). Literatura y cine. Una aproximación comparativa. Cátedra.

Pérez Bowie, José Antonio (2003). La teoría sobre la adaptación cinematográfica de textos literarios. Estado de la cuestión. En La adaptación cinematográfica de textos literarios. Teoria y práctica (pp. 11-30). Plaza Universitaria Ediciones.

Pérez Bowie, José Antonio (2008). Leer el cine. La teoría literaria en la teoría cinematográfica. Ediciones Universidad de Salamanca.

Thorne, Kirsten (1997). El inocente de Mario Lacruz, novela precursora social-policiaca. Hispania (80), 1,31-37.

Villanueva, Darío (2006). Elementos precinematográficos en El Quijote, Estudios Hispánicos, Asociación Coreana de Hispanistas (41), 211-223.

Urrutia, Jorge (1984). Imago litterae. Alfar.

\section{Notas}

1 Como ha estudiado Antoine Jaime (2000: 45), el poeta se refirió al procedimiento cinematográfico en un comentario al poema «Vida retirada» de Fray Luis de León, recogido en su Poesía española. Percibió la técnica yuxtapositiva cinematográfica en la sucesión de la imagen luminosa del huerto a una imagen de miseria y naufragio.

2 En este sentido, han resultado reveladores trabajos como el de C. Nicolás Rubio (1982:181-201), que diferencia, siguiendo a Genette, tres tipos de intertextualidades: lingüística, literaria y semiótica en su análisis de un soneto de Manuel Machado; o como el de Paz Gago (2004:199-232), que aboga por un nuevo enfoque comparativo semiótico-textual para estudiar las convergencias y divergencias entre los sistemas semióticos literario y fílmico.

3 En el quinto aniversario de la muerte de Lacruz, se celebró un homenaje en la Biblioteca Fort Pienc de Barcelona en el que destacados editores y escritores de las letras españolas -Rafael Borràs, Enric Badosa, Rosa Montero, Juan Marsé, Luis Carandell y Eduardo Mendoza- elogiaron su exigencia y calidad como editor, así como la gran modernidad de su obra, concebida en el momento de la posguerra.

4 K. Thorne (1997:31) señala incluso a El inocente como una novela precursora social-policiaca porque comparte ciertas actitudes con la novela policiaca española posfranquista y la novela social de los años cincuenta, dos géneros narrativos comprometidos con la crítica social y la convicción de que la sociedad de su momento era fundamentalmente corrupta. En la novela de Lacruz, se genera un ambiente de persecución y violencia que divide a los personajes según su condición moral y función en el desarrollo de la acción - los inocentes y los culpables, los perseguidos y los cazadores-, poniéndose en evidencia la corrupción de las instituciones y la maleabilidad ética de los sujetos.

5 Vázquez Montalbán (El País, 2000) señaló que «El inocente está más cerca de $E l$ extranjero de Camus que del canon policiaco». También Laura López (2009: 327 y 330) señala que sus personajes están «marcados por la culpa, no ya de lo que les acontece, sino de existir, de haber nacido, perdidos en busca de su propio destino y de un sentido de la vida. (...) Sorprende ya no sólo que estemos ante un escritor desacompasado con respecto a lo que sus coetáneos españoles escribían en el momento, sino que, además, dé mayor relieve a los conflictos del individuo que a los problemas colectivos de la sociedad». 


\section{Sobre la autora}

Profesora Sustituta Interina en el área de Teoría de la Literatura y Literatura Comparada del departamento de Ciencias del Lenguaje en la Universidad de Córdoba (España), ha impartido docencia también en las universidades extranjeras de Pau (Francia) y Poznan (Polonia). Ha publicado dos libros en 2019 y 2020 y cuenta con varios capítulos y una quincena de artículos que versan sobre tres líneas de investigación: estudios de género, interacción de códigos (cine y literatura) y teoría de la narración. 